\title{
PKM PEMETAAN SARANA DAN PRASARANA DESA GRINTING KECAMATAN TULANGAN KABUPATEN SIDOARJO
}

\author{
Jelita Citrawati Jihan ${ }^{1)}$, Suning ${ }^{2)}$, Siti Nuurlaily Rukmana) \\ 1,2,3 Program Studi Perencanaan Wilayah Dan Kota, Fakultas Teknik Sipil Dan Perencanaan \\ Universitas PGRI Adi Buana Surabaya
}

\section{RINGKASAN}

Kegiatan Pengabdian Kepada Masyarakat berjudul PKM Pemetaan Sarana Dan Prasarana di Desa Grinting Kecamatan Tulangan Kabupaten Sidoarjo bertujuan khusus untuk memberikan pengetahuan mengenai manfaat sarana dan prasarana Desa kepada aparat desa dan karang taruna. Kendala yang dialami oleh masyarakat dan Pemerintah Desa Grinting adalah kurangnya pengetahuan tentang pentingnya manfaat informasi sarana dan prasarana desa. Untuk mengatasi permasalahan tersebut akan dilakukan kegiatan adalah penyuluhan mengenai fungsi sarana dan prasarana desa mendukung pengembangan potensi sumber daya alam serta perekonomian.

Kata Kunci: Pemetaan, Sarana dan Prasarana.

\section{PENDAHULUAN}

Desa Grinting Kecamatan Tulangan Kabupaten Sidoarjo, memiliki luas wilayah 972.4 Ha dengan jumlah penduduk sebanyak 3570 jiwa. Kondisi Geografis Desa Grinting terdiri dari hamparan dataran tanah darat. Desa Grinting dilewati oleh aliran sungai yang digunakan untuk lahan pertanian berupa tanaman padi dan tanaman perkebunan. Luas tanah sawah sebesar 97.24 Ha dan tanah kering 31.17. Selain itu adanya potensi lahan pekarangan masyarakat yang dapat dimanfaatkan sebagai media budidaya pisang, perkebunan tumpangsari lombok dan tomat.

Warga masyarakat Desa Grinting Kecamatan Tulangan Sidoarjo sebagian bermata pencaharian sebagai petani dan sisanya ada yang bekerja sebagai buruh pabrik. Peternakan yang ada di Desa Grinting antara lain: lele, sapi dan kambing.

Desa Grinting merupakan salah satu desa di Kecamatan Tulangan Kabupaten Sidoarjo yang berjarak $30 \mathrm{~km}$ dari kampus Universitas PGRI Adi Buana (UNIPA) Surabaya.
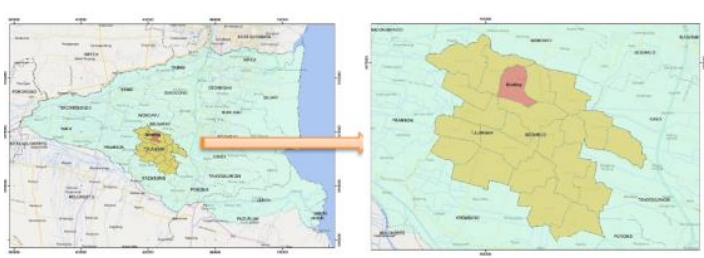

Gambar 1. Peta Orientasi Desa Grinting

Kecamatan Tulangan

Batas-batas administrasi Desa

Grinting adalah sebagai berikut :

Sebelah Barat : Desa Kepuhkemiri

(Kecamatan Tulangan )

Sebelah Timur : Desa Modong

(Kecamatan Tulangan )

Sebelah Selatan : Desa Kematren

(Kecamatan Tulangan )

Sebelah Utara : Desa Kepuhkemiri

(Kecamatan Tulangan )

Jumlah penduduk 3570 jiwa, laki-laki 1821

jiwa dan perempuan 1749 jiwa terdiri dari 3 dusun . Mata pencaharian PNS 9 orang, pedagang 46 orang, buruh pabrik 850 orang, petani 176 orang, tukang 76 orang, buruh tani 26 orang, peternak 5 orang. Home Industri bawang goreng, bumbu instan, plastik.

Menurut Undang-undang nomor 6 Tahun 2014 pasal 8 yaitu Pembentukan desa 
harus memenuhi syarat, salah satunya sarana dan prasarana bagi Pemerintahan Desa dan pelayanan publik. Pembangunan desa harus didukung oleh fasilitas yang memudahkan kegiatan ekonomi dan sosial warga. Pemetaan sarana dan prasarana Desa Grinting adalah kegiatan pembuatan peta yang berbasis pedesaan dibuat berdasarkan aspek sarana dan prasarana yang sesuai dengan peruntukannya. Pemetaan dengan menggunakan pendekatan Sistem Informasi Geografis atau disingkat dengan SIG dan dikenal dengan GIS (Geographic Information System) yaitu pembuatan peta yang dilakukan dengan teknologi berbasis komputer.

Data Infrastruktur, Sarana dan Prasarana

Lingkungan permukiman yang baik di pedesaan adalah dengan ditunjang dengan berbagai sarana dan prasarana. Sarana umum atau fasilitas yang ada di Desa Grinting, seperti fasilitas pendidikan, pasar, sarana kesehatan, sarana peribadatan, sarana ruang terbuka dan sebagainya.

Prasarana transportasi di Desa Grinting adalah berupa jalan aspal dan jalan paving blok yang menghubungkan antar dusun. Pada tahap survey awal, warga Desa Grinting sebenarnya sangat berantusias untuk memanfaatkan media peta untuk mendapatkan informasi terkait sarana dan prasarana desa. Selain itu secara harfiah untuk menginformasikan suatu tempat dibutuhkan perancangan 'signage' atau tanda jalan. Dari berbagai kategori signage, salah satu kategori yang penting adalah signage pada lokasi lingkungan jalan. Berbagai macam signage telah dirancang untuk mengomunikasikan tempat, arah dan informasi lingkungan, baik untuk keperluan lokasi lingkungan dalam (misal: interior gedung perkantoran, rumah sakit, sekolah, museum, dan lain-lain), maupun lokasi lingkungan luar (misal: jalan raya, kompleks perumahan, tempat rekreasi, dan lain-lain).

\section{Permasalahan Mitra}

Berdasarkan kondisi dan situasi tersebut maka permasalahan prioritas masyarakat mitra adalah sebagai berikut:

1. Informasi ketersediaan sarana dan prasarana Desa

2. Tingkat pendidikan dan pengetahuan sangat terbatas tentang informasi yang jelas tentang peta desa untuk lokasi sarana dan prasarana desa. Di setiap jalan, gedung dan sebagainya pasti memiliki tanda-tanda informasi yang disebut signage.

3. Tidak terdapat signage (penanda lokasi).

\section{Justifikasi Prioritas Penanganan}

Justifikasi bersama mitra melalui pemetaan sarana dan prasarana Desa untuk menentukan permasalahan prioritas yang harus ditangani adalah :

1. Kebutuhan masyarakat akan pelayanan informasi sarana prasarana desa belum terpenuhi

2. Belum adanya papan penunjuk arah di Desa Grinting yang harus diikuti dan peta desa.

3. Sebagai acuan dalam penunjuk arah.

Kegiatan ini mengintegrasikan Universitas PGRI Adi Buana Surabaya dan warga masyarakat. Adapun manfaat yang diperoleh bagi instansi yang terkait dalam kegiatan ini

1. Bagi Universitas PGRI Adi Buana Surabaya

2. Dengan adanya penerapan IPTEKS, khususnya memberikan pelatihan tentang pembuatan peta bagi aparat dan warga, hal ini menjadi kontribusi Universitas PGRI Adi Buana Surabaya sebagai instansi perguruan tinggi dapat melaksanakan tri dharma perguruan tinggi yang ke tiga yaitu Pengabdian Pada masyarakat (PPM).

2. Bagi Masyarakat

Melalui kegiatan ini masyarakat memperoleh pengetahuan tentang fungsi sarana dan prasarana desa, selain itu pentingnya penanda jalan (signage), sehingga menimbulkan kesadaran bahwa informasi penting untuk memberikan arah di suatu lingkungan atau kawasan.

\section{METODOLOGI}

Mengacu pada justifikasi prioritas penanganan bersama mitra, maka solusi utama yang akan diterapkan adalah : "PKM Pemetaan Sarana dan Prasarana Desa Grinting Kecamatan Tanggulangin Kabupaten Sidoarjo.

Tujuan dari kegiatan yang dilakukan adalah :

1. Mengetahui persebaran sarana dan prasarana Desa 
2. Untuk pendataan

3. Signage atau penanda jalan

Untuk mencapai tujuan I, yaitu pemetaan sarana dan prasarana Desa Adapun rincian kegiatan untuk metode ini adalah sebagai berikut:

1. Penjelasan terkait dengan sarana dan prasarana

2. Penjelasan terkait dengan Proses survey lokasi sebagai tahap awal yang sangat penting untuk mengetahui letak sapras dan keadaan lingkungan.

Untuk mencapai tujuan II, yaitu memberikan informasi terkait dengan proses pendataan dan proses pengolahan peta. Adapun rincian kegiatan untuk metode ini adalah sebagai berikut:

1. Penjelasan terkait proses pengumpulan data

2. Penjelasan terkait dengan pengolahan data

3. Pelatihan mengenai tahapan proses layouting peta melalui perangkat lunak Sistem Informasi Geografis

Untuk mencapai tujuan ke III, yaitu merancang signage jalan. Adapun rincian kegiatan untuk metode ini adalah sebagai berikut :

1. Penjelasan terkait gambaran umum mengenai perancangan konsep signage.

2. Pelatihan mendesain tanda jalan.

Tahapan monitoring dan penyusunan laporan dilakukan sebagai berikut :

a. Pelaksanaan monitoring kegiatan.

b. Laporan hasil penerapan kegiatan.

c. Pemecahan masalah terkait hambatan dan tingkat keberhasilan.

d. Evaluasi Kegiatan.

e. Pembuatan laporan kegiatan.
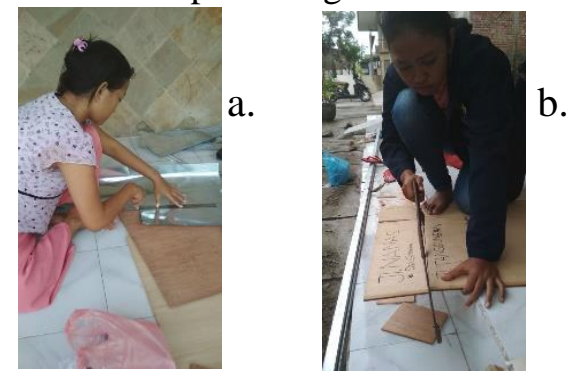

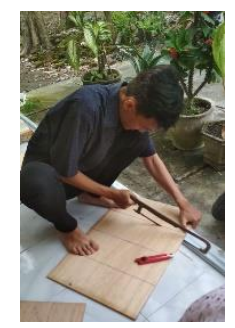

c.

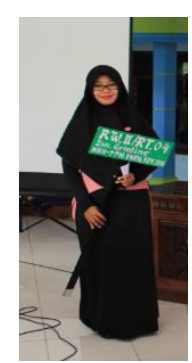

d
Gambar 2. Proses persiapan pembuatan plakat jalan untuk pembatas desa

Penggunaan teknolgi yang digunakan PKM Pemetaan Sarana dan Prasarana Desa Grinting dilakukan dengan cara :

1. Menggunakan perangkat lunak pembuatan peta sistem informasi geografis.

2. Merancang penanda jalan sebagai penunjuk arah.

\section{A. Partisipasi Mitra dan Warga}

Ketua PKK dan ketua karang taruna sebagai mitra dalam program PKM ini bersedia memberikan bantuan kepada pihak penyusul PKM dalam bentuk:

1. Penyedia ruang pertemuan pada saat penyuluhan dan pelatihan

2. Kesediaan tenaga pada penerapan IPTEKS untuk pelatihan perangkat lunak SIG

3. Ketersediaan tenaga pada pembuatan penanda jalan.

\section{HASIL DAN PEMBAHASAN}

Pelaksanaan program PENGABDIAN KEPADA MASYARAKAT (PKM) dimulai setelah dilakukan penandatanganan kontrak antara ketua pelaksana dengan LP2M Universitas PGRI. Langkah awal yang dilakukan adalah koordinasi dengan Mitra dan Mahasiswa/mahasiswa KKN - PPM di Desa Grinting Kecamatan Tulangan Sidoarjo. Pelaksanaan PKM ini dilakukan dengan memberikan penyuluhan kepada warga tentang pemetaan sarana prasarana desa dan tahapan pembuatan peta. 
Tabel 1. Data sapras di Desa Grinting Tahun 2018

\begin{tabular}{|c|c|c|c|c|}
\hline No & Sarana dan prasarana & Jenis & Fungsi & Panjang \\
\hline \multicolumn{5}{|c|}{ Jalan } \\
\hline 1 & Jl. Grinting & Aspal & lokal primer & 2521 \\
\hline 2 & Jl. Hasanudin & Aspal & lokal primer & 782 \\
\hline 3 & & Paving & lingkungan & 6962 \\
\hline 4 & & Tanah & lingkungan & 868 \\
\hline Total & & & & 11133 \\
\hline \multicolumn{5}{|c|}{ Irigasi } \\
\hline & & Kuarter & 1454 & \\
\hline & & Sekunder & 2567 & \\
\hline & & tersier & 2947 & \\
\hline Total & & & 6968 & \\
\hline \multicolumn{5}{|c|}{ Peribadatan } \\
\hline 1 & \multirow{6}{*}{ Mushollah } & Darul amin, An nisa, $\mathrm{Al}$ falah & RW 1 & 3 \\
\hline 2 & & $\mathrm{Al}$ muttaqim & RW 2 & 1 \\
\hline 3 & & Al Badar,Nurul Huda & RW 3 & 2 \\
\hline 4 & & $\mathrm{Al}$ amin, Darul Qoror, Darul Muttaqim, & RW 4 & 5 \\
\hline 5 & & Nurul Fadhilah, Al Banjari, Al Fattah & RW 5 & 3 \\
\hline 6 & & & RW 6 & 0 \\
\hline 7 & \multirow[b]{2}{*}{ Masjid } & Nurul Falah & RW 5 & 1 \\
\hline 8 & & An Nur & RW 3 & 1 \\
\hline \multicolumn{2}{|c|}{ Total } & & & 16 \\
\hline \multicolumn{5}{|c|}{ Pendidikan } \\
\hline 1 & Non Formal & Pondok pesantren & & 1 \\
\hline 2 & Formal & SDN 1 grinting & & 1 \\
\hline 3 & Formal & Tk darma Wanit & grinting & 1 \\
\hline Total & & & & 3 \\
\hline
\end{tabular}

Sumber: Hasil Survey, 2017

Validasi di lapangan (ground truth) dilakukan untuk mengecek kebenaran hasil analisis, dan pengamatan jenis-jenis penggunaan lahan/vegetasi di sekitarnya dan penyebarannya (Jihan, 2016).

Secara rinci pelaksanaan program PENGABDIAN KEPADA MASYARAKAT (PKM) adalah sebagai berikut:

1. Survei Primer

Persiapan yang dilaksanakan tim pelaksana adalah survey lapangan untuk sarana prasarana di wilayah Desa Grinting. Survey lokasi berupa observasi wilayah program Pengabdian Kepada Masyarakat (PKM).

2. Persiapan Pemetaan Sarana Dan Prasarana
Setelah melakukan survey awal dan penetapan permasalahan yang akan diangkat dan diselesaikan di lokasi PKM tim melakukan koordinasi dengan pihak pemerintahan desa dalam hal ini Kepala Desa Grinting dan kader PKK. Selanjutnya dipilih lokasi di Balai Desa Grinting untuk pelaksanaan PKM ini. Pemilihan lokasi dilandasi pada posisi balai desa Grinting yang berada dekat dengan beberapa dusun di desa tersebut. Persiapan sarana dan prasanana di lokasi dilaksanakan oleh aparat desa dan dibantu dengan mahasiswa peserta KKN PPM.

3. Pengadaan Alat Dan Bahan

Proses penyuluhan tentang manfaat sarana prasarana Desa dan pembuatan peta yang 
dilakukan oleh tim pelaksana PKM dari Teknik Perencanaan Wilayah Dan Kota, adalah dengan memberikan materi penyuluhan yang dipresentasikan dihadapan peserta PKM dengan menggunakan alat pendukung laptop.

4. Presentasi Penyuluhan

Penyuluhan dilakukan dengan tema besarnya adalah memberikan informasi mengenai manfaat pemetaan sarana dan prasarana desa Grinting .

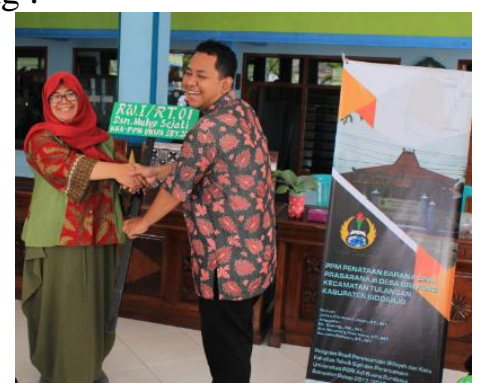

Gambar 3. Penyerahan penanda jalan oleh tim pelaksana, ukuran besar dan kualitas baik/ mudah dilihat, dapat dibaca dari jarak jauh.

Gambar di atas merupakan penanda jalan yang disampaikan oleh Jelita Citrawati Jihan. Materi penyuluhan diberikan secara praktis dan mudah dimengerti oleh para peserta karena ditunjukkan dengan gambar mafaat sarana prasarana Desa Grinting secara langsung.

\section{Pelaksanaan Pada Masyarakat}

Pemaparan pemetaan sarana dan prasarana PPM dilakukan selama tiga jam mulai jam 09.00 WIB sampai jam 12.00 WIB. Partisipasi dan pelatihan terstruktur dilakukan selama 2 minggu dengan bantuan teman-teman mahasiswa KKN di Desa Grinting.

3. Pemantauan Hasil Pelaksanaan

Pemantauan pelaksanaan dilakukan tanggal 11 September 2017, setelah satu minggu pelaksanaan penyuluhan di Desa Grinting pmantauan dilakukan dengan cara meninjau langsung pada lokasi tempat pemberian penanda jalan di Desa Grintingg. Pemantauan ini dilakukan oleh tim PKM Fakultas Teknik, bersama dengan aparat desa dan tim PKK. Aparat desa dan kader PKK cukup optimal namun belum maksimal dalam upaya pelaksanaan pemetaan sarana dan prasarana, karena memang membutuhkan waktu lama untuk menerapkan penunjuk arah dan pembuatan peta..

4. Tim Pelaksana Program Penerapan Program Pengabdian Kepada Masyarakat (PKM)

Tim pelaksana yang akan melaksanakan Pengabdian Kepada Masyarakat (PKM) di Desa Grinting Kecamatan Tulangan Sidoarjo adalah dosen-dosen di lingkungan Fakultas teknik Universitas PGRI Adi Buana Surabaya Selanjutnya pihak Universitas PGRI Adi Buana memberikan kenang-kenangan dalam bentuk tanda jalan yang akan dipasang di jalan Desa Grinting sehingga masyarakat secara teknis dapat melaksanakannya.

1. Identifikasi sarana dan prasarana

Warga masyarakat di Desa Grinting kurang memahami tentang pentingnya manfaat Sapras desa. Warga belum mendapat informasi sarana dan prasarana desa yang dapat memajukan desa sehingga belum tertangani secara kelembagaan.

\section{Kondisi Akhir}

Setelah satu minggu dari pelaksanaan penyuluhan tentang manfaat sarana dan prasarana Desa, masyarakat sudah bisa mengerti namun masih belum dibentuk kelembagaan secara khusus yang menangani masalah sarana dan prasarana di desa Grinting. Tetapi warga sudah mulai mengerti potensi sapras di Desa Grinting sebagai penunjang pembangunan Desa.

\section{KESIMPULAN}

Pengabdian Kepada Masyarakat (PKM) berupa PKM Pemetaan Sarana dan Prasarana di Desa Grinting Kecamatan Tulangan Sidoarjo berjalan dengan baik. Hasil yang diperoleh dari pelaksanaan ini adalah Masyarakat Desa Grinting menjadi mengerti dan memahami bagaimana sarana dan prasarana desa dapat mendukung perekonomian serta pengembangan potensi sumber daya alam desa terutama pasar dan irigasi karena itu sangat penting dikelola misalnya Kelembagaan Kader Lingkungan. 


\section{DAFTAR PUSTAKA}

Jihan, J. C. (2016). Pemetaan Jaringan Jalan Terhadap Aktivitas Perdagangan Dan Jasa Berbasis SIG Di Kecamatan Sukolilo Surabaya Timur. Waktu, 14. Retrieved from

http://jurnal.unipasby.ac.id/index.php/wak tu/article/download/137/49

Raharjo, B, Ikhsan, M. (2015). Belajar ArcGIS Desktop 10 . Geosiana Press, Banjarmasin.

Suseno, Deky A, Sunarto. (2016). Analisis Perencanaan Pembangunan Desa Berbasis Undang-Undang Desa No 6 Tahun 2014 Di Kecamatan Gunungpati Kota Semarang. Jurnal Stie, Vol. 8, Semarang.

Diunduh pada tanggal 19 April 2018, pukul 09.49 WIB

http://kompak.or.id/userfiles/publication/dow nload/Buku_Sarana_Prasarana_Desa.pdf

Undang-undang Nomor 6 Tahun 2014 tentang Desa

\section{UCAPAN TERIMAKASIH}

Penulis mengucapkan terima kasih kepada Universitas PGRI Adi Buana yang telah memberikan dana Pengabdian Kepada Masyarakat kepada penulis, serta kepada Pemerintah daerah setempat yang telah memberikan beberapa jenis data yang digunakan dalam penelitian ini.

\section{Lampiran}

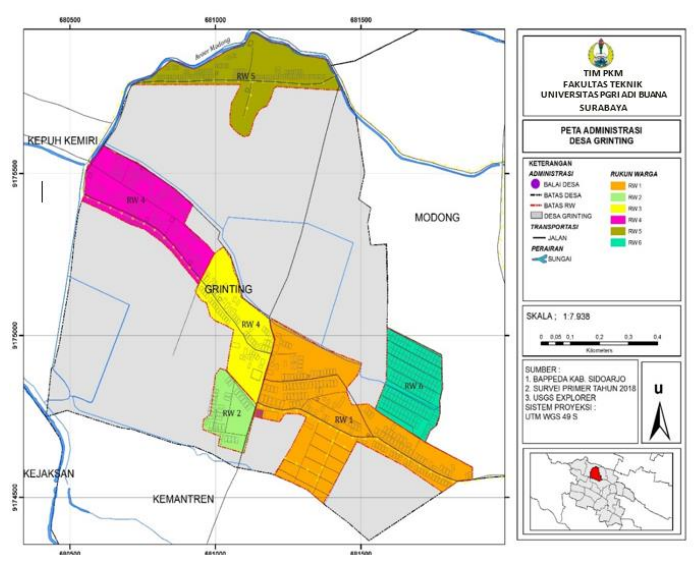

Gambar 4. Peta Administrasi Desa Grinting

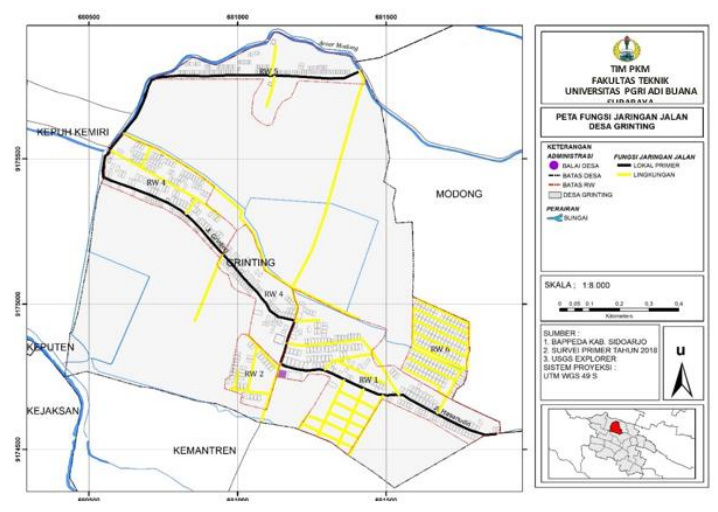

Gambar 5. Peta Fungsi Jaringan Jalan Desa Girnting

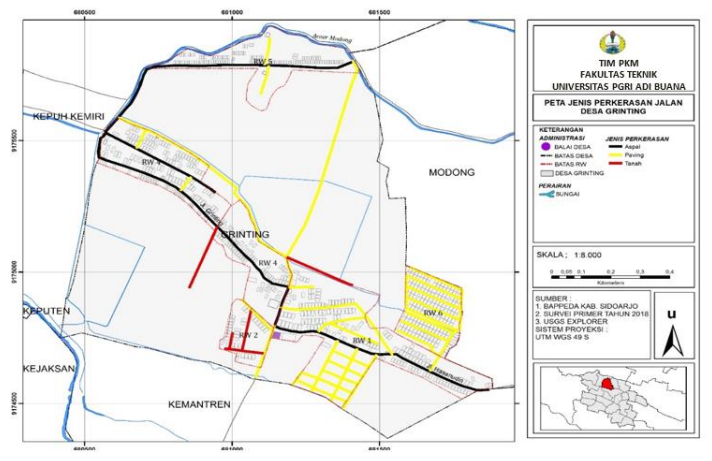

Gambar 6. Peta jenis perkerasan jalan Desa Grinting

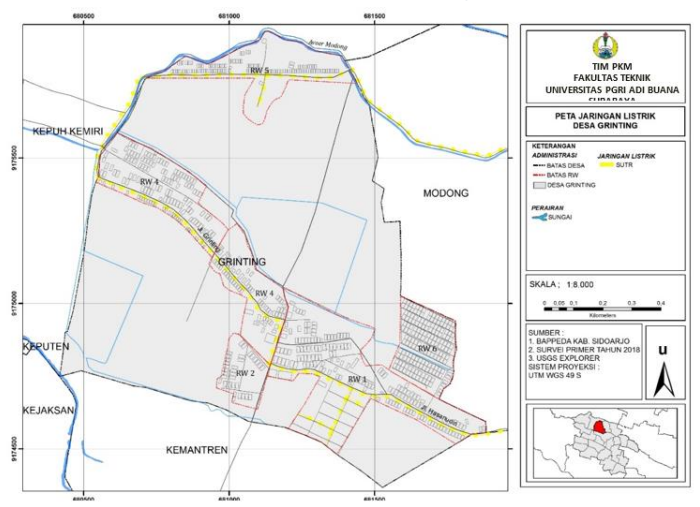

Gambar 7. Peta jaringan listrik Desa Grinting 


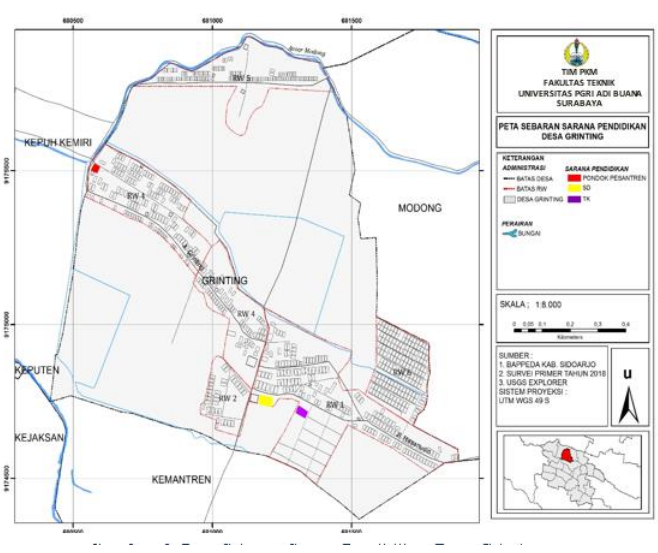

Gambar 8. Peta Sebaran Sarana Pendidikan Desa Grinting

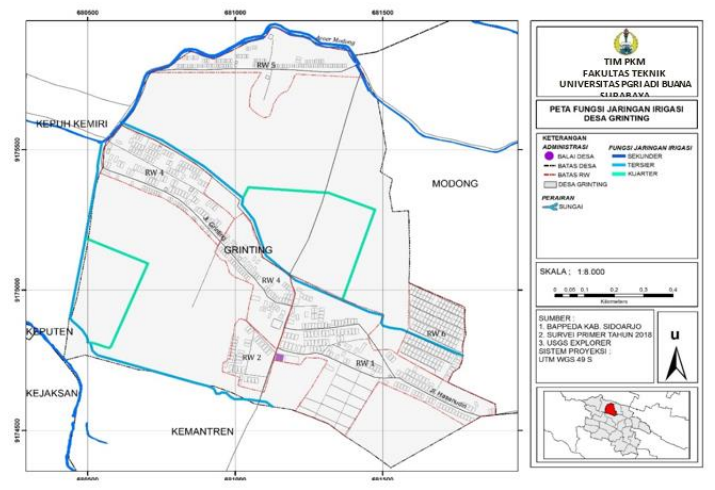

Gambar 9. Peta Fungsi Jaringan Irigasi Desa Grinting

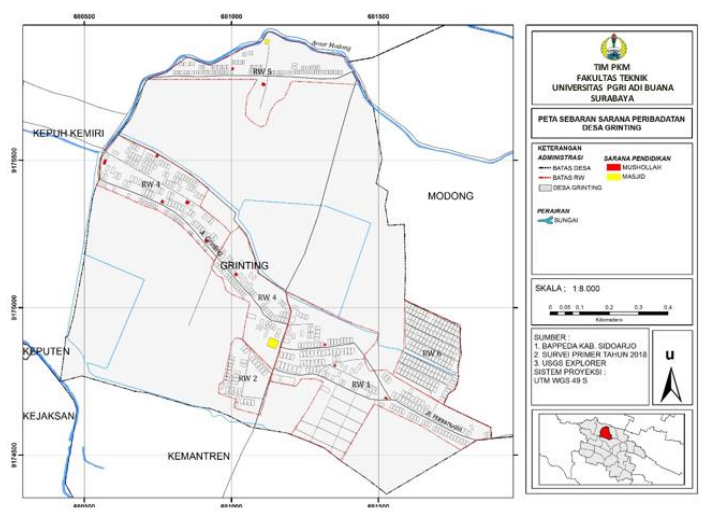

Gambar 10.Peta Sebaran Sarana Peribadatan Desa Grinting 